\title{
Beneficial Effects of the Coronary Collateral Circulation on Tachycardia-Induced Myocardial Ischemia during Experimental Coronary Stenosis
}

\author{
Susumu Sakamoto, M.D., Mitsuhiro Yokoyama, M.D., \\ Hozuka Akita, M.D., Seinosuke Kawashima, M.D., \\ Toshio Okada, M.D., Tetsuo Mizutani, M.D., * and \\ Hisashi Fukuzaki, M.D.
}

\section{SUMmaRY}

This study was designed to determine whether coronary collaterals have preventive effects on tachycardia-induced myocardial ischemia under partial restriction of proximal coronary artery inflow. Studies were carried out in dogs with developed coronary collaterals and control dogs. ST-elevation in epicardial and intramyocardial electrograms was used for assessing the degree of regional myocardial ischemia. In control dogs with coronary constriction ( $80 \%$ reduction of i.d.) pacing-induced tachycardia produced significant ST-elevation, $1.48 \pm 0.17 \mathrm{mV}$ in the inner layer and $0.79 \pm 0.29 \mathrm{mV}$ in the middle layer at a cardiac rate of 150 / $\min , 3.58 \pm 0.38 \mathrm{mV}$ in the inner layer, $2.73 \pm 0.38 \mathrm{mV}$ in the middle layer, and $1.93 \pm 0.36 \mathrm{mV}$ in the outer layer at a rate of $180 /$ min. In dogs with moderate collaterals ST-segment elevation was only $1.41 \pm 0.18 \mathrm{mV}$ in the inner layer and $0.96 \pm 0.24 \mathrm{mV}$ in the middle layer at a rate of $180 / \mathrm{min}$. In dogs with abundant collaterals there was no significant ST-elevation during tachycardia. These findings indicate that blood supply to the affected myocardium via developed collaterals is sufficient to meet graded increases in metabolic requirements under the condition of limited coronary flow reserve in an experimental model simulating angina pectoris.

\section{Additional Indexing Words:}

Coronary stenosis Stress condition Myocardial ischemia Coronary collaterals Electrographic changes

MYCARDIAL ischemia occurs due to an imbalance between oxygen delivery and myocardial metabolic requirements. Patients with

From the First Department of Internal Medicine, School of Medicine, Kobe University, Kobe.

* National Kobe Hospital.

Address for reprint: Susumu Sakamoto, M.D., First Department of Internal Medicine, Kobe University Hospital, 7-chome, Kusunoki-cho, Chuo-ku, Kobe 650, Japan.

Received for publication April 27, 1982. 
coronary artery discase who have partially expended their coronary flow reserve to meet myocardial metabolic demands even under resting condition would be less capable of additional coronary vasomotor compensation during stress. In these patients, pacing-induced tachycardia might produce myocardial ischemia.

Most of the previously conducted experimental studies have been confined to a description of the fluid dynamics of coronary artery stenosis. ${ }^{1)}$ Recent studies from our laboratory have documented the quantitative relationship between graded coronary obstruction and regional blood flow and intramyocardial gas tensions and its resultant effects on electrophysiologic abnormalities during the resting state. ${ }^{21-4)}$ It was thus demonstrated that STsegment elevation on the intramyocardial electrogram reflected myocardial ischemia in the corresponding region.

It is well known that gradual coronary occlusion in animals induces collateral vessel development without myocardial infarct formation. ${ }^{5)}$ The myocardium supplied by a totally occluded coronary artery may be perfused adequately through well-developed collateral vessels under resting conditions. To date however, there is a paucity of data defining the physiological role of the coronary collateral circulation in an experimental model of angina pectoris.

This study was undertaken to examine electrophysiologic abnormalities in response to an increase in myocardial metabolic demands under partial restriction of proximal coronary artery inflow, and to study the preventive effects of coronary collateral circulation on myocardial ischemia induced by tachycardia.

\section{Methods}

The experiments were carried out in 29 adult mongrel dogs weighing $9-18 \mathrm{Kg}$. A control group of 13 normal dogs with poor collaterals and a group of 16 dogs with developed collaterals were included in this study.

Sixteen dogs were subjected to chronic coronary artery occlusion before the period of experimental observation using the following technique. After anesthesia with sodium pentobarbital, $25 \mathrm{mg} / \mathrm{Kg}$, i.v. and ventilation by a mechanical respirator, the chest was opened in the fourth left intercostal space and the heart exposed under sterile conditions. The proximal portion of the left circumflex coronary artery was dissected free and an ameroid constrictor of appropriate size was placed around the vessel as described previously. ${ }^{6}$ The chest was closed in layers and the dogs were allowed to recover. They were reoperated on 19-25 days later. 


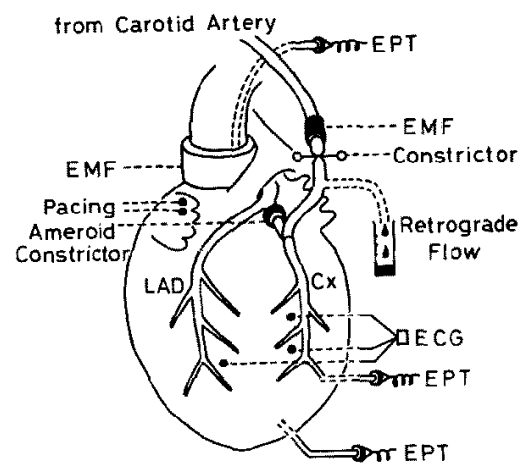

Fig. 1. Schematic diagram of the experimental preparation. EPT= electric pressure transducer; $\mathbf{E M F}=$ electromagnetic flowmeter; $\mathrm{ECG}=\mathrm{elec}$ trogram; $\mathrm{LAD}=$ left anterior descending artery; $\mathrm{Cx}=$ circumflex artery.

All dogs were anesthetized with sodium pentobarbital, $30 \mathrm{mg} / \mathrm{Kg}$, i.v. and ventilated with room air and supplementary oxygen using a volume respirator to maintain arterial gas tensions within physiological ranges. A left thoracotomy was done in the fifth intercostal space and the heart was suspended in a pericardial cradle. The experimental preparation is shown in Fig. 1. The proximal part of the circumflex artery (or the segment of the vessel distal to the ameroid constrictor in the chronic preparation) was isolated and encircled with silk threads. Immediately after ligation of the circumflex artery, its distal portion was cannulated and autoperfused from the left carotid artery through silicon elastomer tubing $(2.8 \mathrm{~mm}$ i.d.). The tube was ligated by a snare constrictor attached to a machinist's micrometer to create a calibrated focal constriction equivalent to an $80 \%$ reduction of the internal diameter. The accuracy of the degree of constriction was confirmed beforehand using paraffin casts. A polyethylene catheter was inserted into the aortic arch through a femoral artery for monitoring aortic blood pressure. A similar catheter was inserted into the left ventricular cavity through a stab wound in the apical dimple for measurement of left ventricular pressure. A distal branch of the circumflex coronary artery was cannulated with a third polyethylene tube to record peripheral coronary pressure. Aortic and coronary blood flow were measured with an electromagnetic flowmeter. During a brief occlusion of the proximal portion of the autoperfusion graft, retrograde pressure was recorded from the peripheral circumflex artery and retrograde flow was measured from the autoperfusion graft. These parameters were used as indices of the development of the coronary collateral vessels. All hemodynamic parameters were recorded using a direct writing recorder. After the sinus node was crushed, the right atrium was stimulated with a pacemaker. Usually, the heart rate was maintained at $100 / \mathrm{min}$ 
during rest. Four pairs of epicardial and intramyocardial electrodes with five recording sites were used in this study as reported previously. ${ }^{2)-4)}$ Three pairs were placed in the left circumflex area $(\mathrm{Cx}$ area) and the other was placed in the area of the anterior descending artery (LAD area) of the left ventricle. Electrograms were obtained at a paper speed of $50 \mathrm{~mm} / \mathrm{sec}$ and a sensitivity of $1 \mathrm{mV} / \mathrm{mm}$. ST-segment voltage was measured at $0.06 \mathrm{sec}$ after the end of the S-wave. A period of $60 \mathrm{~min}$ was allowed for the injury current due to the insertion of the intramyocardial electrode to be stabilized. In the resting condition without constriction of the circumflex coronary artery, ST-segment voltage in electrograms from two areas was measured and analysed. ST-elevation was calculated as the change $(\Delta \mathrm{STmV})$ from STsegment voltage in this resting condition. The mean value of three $\Delta \mathrm{ST}$ from the $\mathrm{Cx}$ area was used for $\triangle \mathrm{ST}$ of the $\mathrm{Cx}$ area. In control dogs with and without constriction, the heart rate was increased by atrial pacing to rates of 120,150 , and 180/min, respectively, with each period of pacing maintained for 5 min. After electrograms and hemodynamic parameters were recorded, the pacing rate was returned to the resting level. After waiting a minimum of 10 min until hemodynamic and electrocardiographic changes returned to the control level, the examination was repeated at the next higher pacing rate. The dogs with developed collaterals produced by chronic coronary occlusion were examined using the same protocol only in the presence of circumflex artery constriction. In all experiments, anticoagulation was achieved by an initial intravenous injection of 5,000 $\mathrm{U}$ heparin and subsequent injections of $1,000 \mathrm{U}$ every $30 \mathrm{~min}$. After completion of the experimental studies, the animals were sacrificed and their hearts removed. No myocardial infarcts were detected macroscopically.

All values are expressed as mean \pm standard error and statistical analysis was performed using Student's t-test.

\section{RESULTS}

1. Functional indices of coronary collateral development

The dogs with developed collaterals produced by chronic coronary occlusion were divided into 2 groups. Those 10 animals which showed retrograde pressures of less than $45 \mathrm{mmHg}$ were designated as dogs with moderate collaterals. The other 6 showed retrograde pressures greater than $45 \mathrm{mmHg}$ and were designated as having abundant collaterals. The mean retrograde pressure $(\mathrm{mmHg})$ was $22.3 \pm 1.3$ in control dogs with poor collaterals, $34.6 \pm$ 2.3 in dogs with moderate collaterals and $52.2 \pm 2.4$ in dogs with abundant collaterals (Fig. 2). The retrograde flow rates $(\mathrm{ml} / \mathrm{min}$ ) were $3.0 \pm 0.3,10.1$ 

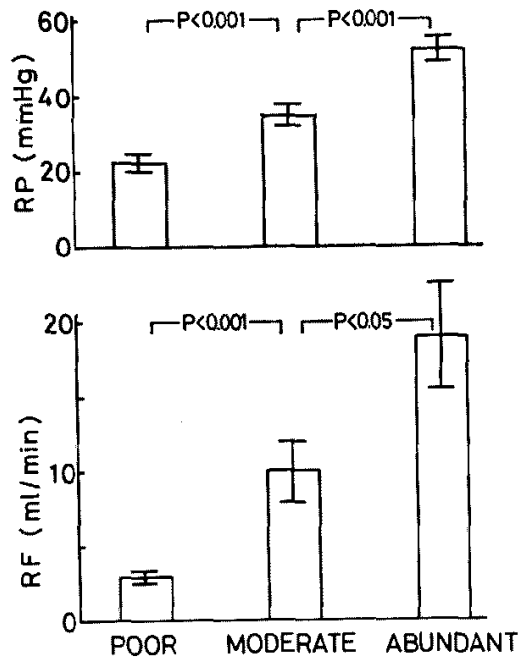

Fig. 2. Functional indices of coronary collateral development among 3 groups of dogs with poor, moderate, and abundant collaterals. $\mathrm{RP}=$ retrograde pressure; $\mathrm{RF}=$ retrograde flow.

Table I. Systemic and Coronary Hemodynamic Parameters

\begin{tabular}{|c|c|c|c|c|c|c|}
\hline & $\begin{array}{c}\text { PR } \\
(/ \min )\end{array}$ & $\underset{(\mathrm{mmHg})}{\mathrm{mAP}}$ & $\underset{(\mathrm{ml} / \mathrm{min})}{\mathrm{AF}}$ & $\begin{array}{l}\text { LVEDP } \\
(\mathrm{mmHg})\end{array}$ & $\begin{array}{c}\mathrm{mPCP} \\
(\mathrm{mmHg})\end{array}$ & $\begin{array}{c}\mathrm{CBF} \\
(\mathrm{ml} / \mathrm{min})\end{array}$ \\
\hline \multirow{4}{*}{$\begin{array}{l}\text { Poor without } \\
\text { constriction }\end{array}$} & 100 & $97.6 \pm 4.1$ & $854 \pm 66$ & $4.8 \pm 0.5$ & $94.0 \pm 4.0$ & $21.1 \pm 1.6$ \\
\hline & 120 & $99.3 \pm 3.9$ & $867 \pm 67$ & $5.1 \pm 0.5$ & $95.5 \pm 3.7$ & $22.2 \pm 1.5^{*}$ \\
\hline & 150 & $99.8 \pm 4.0$ & $930 \pm 78$ & $5.1 \pm 0.6$ & $95.5 \pm 4.1$ & $24.6 \pm 1.6^{* * *}$ \\
\hline & 180 & $98.5 \pm 4.0$ & $912 \pm 72$ & $6.0 \pm 0.6$ & $95.1 \pm 4.1$ & $27.3 \pm 1.7^{* * *}$ \\
\hline \multirow{4}{*}{$\begin{array}{l}\text { Poor with } \\
\text { constriction }\end{array}$} & 100 & $96.9 \pm 3.4$ & $779 \pm 65$ & $4.5 \pm 0.3$ & $57.1 \pm 1.7$ & $15.7 \pm 1.4$ \\
\hline & 120 & $97.6 \pm 3.7$ & $790 \pm 69$ & $4.6 \pm 0.3$ & $56.9 \pm 1.6$ & $15.7 \pm 1.2$ \\
\hline & 150 & $96.7 \pm 3.1$ & $837 \pm 70$ & $5.4 \pm 0.6$ & $55.4 \pm 1.7$ & $16.0 \pm 1.5$ \\
\hline & 180 & $96.6 \pm 3.6$ & $816 \pm 64$ & $6.2 \pm 0.8 * *$ & $54.3 \pm 1.5$ & $16.2 \pm 1.8$ \\
\hline \multirow{4}{*}{$\begin{array}{l}\text { Moderate with } \\
\text { constriction }\end{array}$} & 100 & $95.8 \pm 2.9$ & $782 \pm 64$ & $5.1 \pm 0.5$ & $55.6 \pm 2.0$ & $13.0 \pm 1.4$ \\
\hline & 120 & $95.2 \pm 3.0$ & $824 \pm 65$ & $5.0 \pm 0.7$ & $55.8 \pm 1.8$ & $12.8 \pm 1.4$ \\
\hline & 150 & $94.0 \pm 2.9$ & $850 \pm 74$ & $5.3 \pm 0.7$ & $55.0 \pm 1.5$ & $13.0 \pm 1.3$ \\
\hline & 180 & $94.4 \pm 3.3$ & $849 \pm 94$ & $7.1 \pm 0.9^{* * *}$ & $54.0 \pm 1.6$ & $13.8 \pm 1.5$ \\
\hline \multirow{4}{*}{$\begin{array}{l}\text { Abundant with } \\
\text { constriction }\end{array}$} & 100 & $97.3 \pm 1.8$ & $890 \pm 89$ & $4.7 \pm 0.5$ & $58.7 \pm 1.3$ & $11.8 \pm 1.9$ \\
\hline & 120 & $96.2 \pm 1.5$ & $897 \pm 91$ & $4.8 \pm 0.4$ & $58.7 \pm 1.1$ & $11.7 \pm 2.0$ \\
\hline & 150 & $96.0 \pm 1.4$ & $936 \pm 96$ & $5.6 \pm 0.8$ & $57.7 \pm 1.3$ & $12.0 \pm 1.6$ \\
\hline & 180 & $95.0 \pm 1.2$ & $940 \pm 96$ & $6.4 \pm 0.8^{*}$ & $56.7 \pm 1.2$ & $12.1 \pm 1.8$ \\
\hline
\end{tabular}

$\mathrm{mAP}=$ mean aortic pressure $; \mathrm{AF}=$ aortic flow $; \mathrm{LVEDP}=$ left ventricular end-diastolic pressure ; $\mathrm{mPCP}=$ mean peripheral coronary pressure $\mathrm{CBF}=$ coronary blood flow; $\mathrm{PR}=$ pacing rate.

$*$, **, ***: significantly different from resting values at $\mathrm{p}<0.05, \mathrm{p}<0.01$, and $\mathrm{p}<0.001$. 
\pm 1.9 , and 19.0 \pm 3.7 , respectively. These differences were statistically significant.

2. Systemic and coronary hemodynamic observations

All hemodynamic parameters are presented in Table I. At rest there were no differences in aortic blood pressure, aortic blood flow, and left ventricular end-diastolic pressure (LVEDP) among the 3 groups either with or without constriction of the circumflex coronary artery. Increasing the pacing rate did not induce any significant changes in aortic blood pressure or aortic flow. However, LVEDP was significantly elevated in all groups at a rate of $180 / \mathrm{min}$.

Constriction of the circumflex coronary artery in the resting condition produced a pressure gradient across the stenosis of $39.8 \pm 3.3 \mathrm{mmHg}$ in control dogs, $40.2 \pm 3.6 \mathrm{mmHg}$ in dogs with moderate collaterals, and $38.7 \pm 2.0$ $\mathrm{mmHg}$ in dogs with abundant collaterals. There were no significant differences among the 3 groups.

Pacing-induced tachycardia produced a significant increment in circumflex coronary blood flow in control dogs without constriction $(r=0.9)$; however, no significant change was induced in any of the 3 groups following constriction.

3. Electrocardiographic ST-segment changes in control dogs

In control dogs without constriction, pacing-induced tachycardia in-

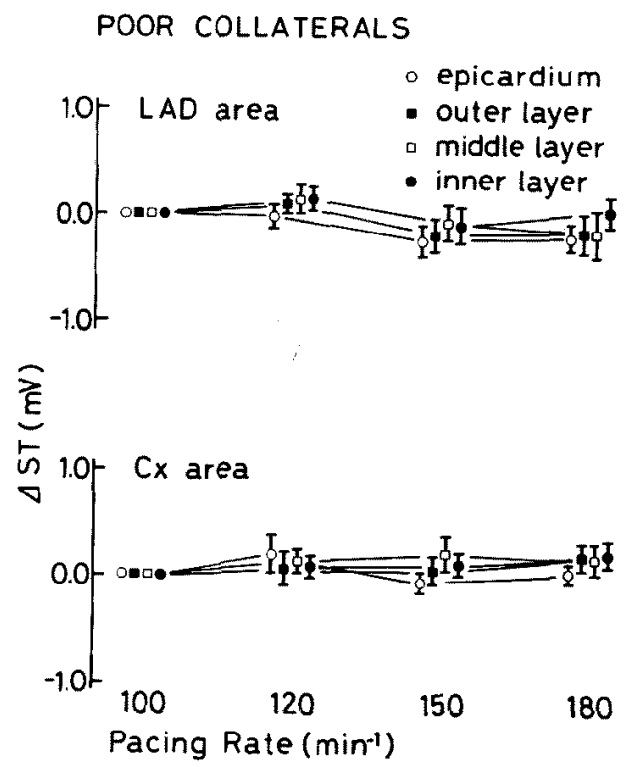

Fig. 3. $\triangle S T$ changes from LAD and $\mathrm{Cx}$ areas produced by pacing-induced tachycardia in the absence of coronary constriction in control dogs with poor collaterals. $\mathrm{LAD}=$ left anterior descending artery; $\mathrm{Cx}=$ circumflex artery. 
duced no significant ST-elevation in electrograms from any recording site in the LAD and Cx areas (Fig. 3).

In control dogs, constriction of the circumflex coronary artery did not affect ST-segment voltage in the resting condition; however, pacing-induced tachycardia did produce significant increases in ST-segment voltage in the Cx area as shown in Figs. 4 and 5. At a pacing rate of $150 / \mathrm{min}, \Delta \mathrm{ST}$ in electrograms from the $\mathrm{Cx}$ area increased by $1.48 \pm 0.17 \mathrm{mV}$ in the inner layer and $0.79 \pm 0.29 \mathrm{mV}$ in the middle layer. At a pacing rate of $180 / \mathrm{min}, \Delta \mathrm{ST}$ from the $\mathrm{Cx}$ area increased by $3.58 \pm 0.38 \mathrm{mV}$ in the inner layer, $2.73 \pm 0.38 \mathrm{mV}$ in the middle layer, and $1.93 \pm 0.36 \mathrm{mV}$ in the outer layer. The ST-segment in epicardial electrograms showed a modest elevation at a rate of $180 / \mathrm{min}$, but this elevation was not significant. Accordingly, pacing-induced tachycardia produced transmural or subendocardial myocardial ischemia which was detectable on epicardial and intramyocardial electrograms. The STsegments in electrograms of the epicardium and outer layer from the LAD area were depressed reciprocally.

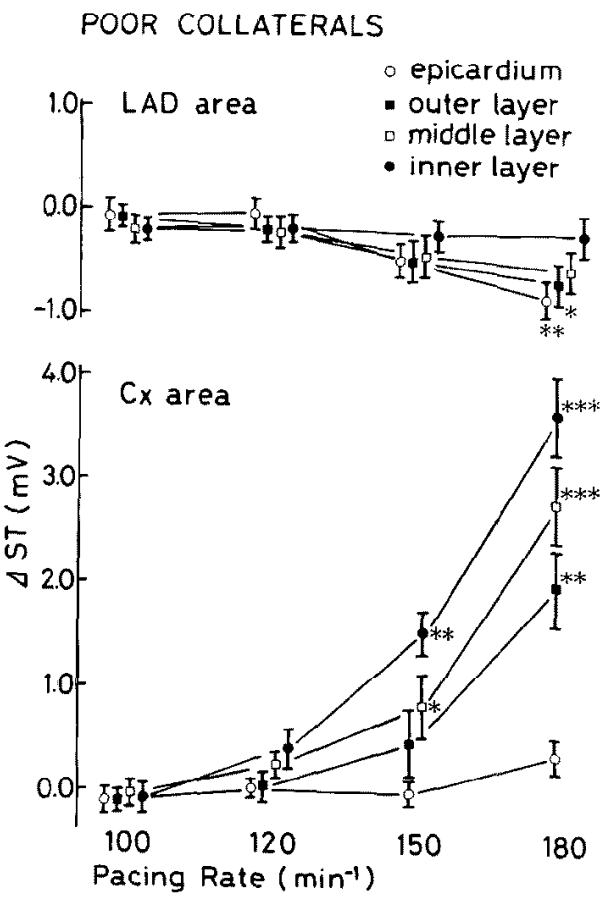

Fig. 4. $\Delta \mathrm{ST}$ changes from LAD and $\mathrm{Cx}$ areas produced by pacing-induced tachycardia in the presence of coronary constriction in control dogs with poor collaterals. $L A D=$ left anterior descending artery; $C x=$ circumflex artery. ***,***: significantly different from resting values at $\mathrm{p}<0.05, \mathrm{p}<$ 0.01 , and $\mathrm{p}<0.001$. 


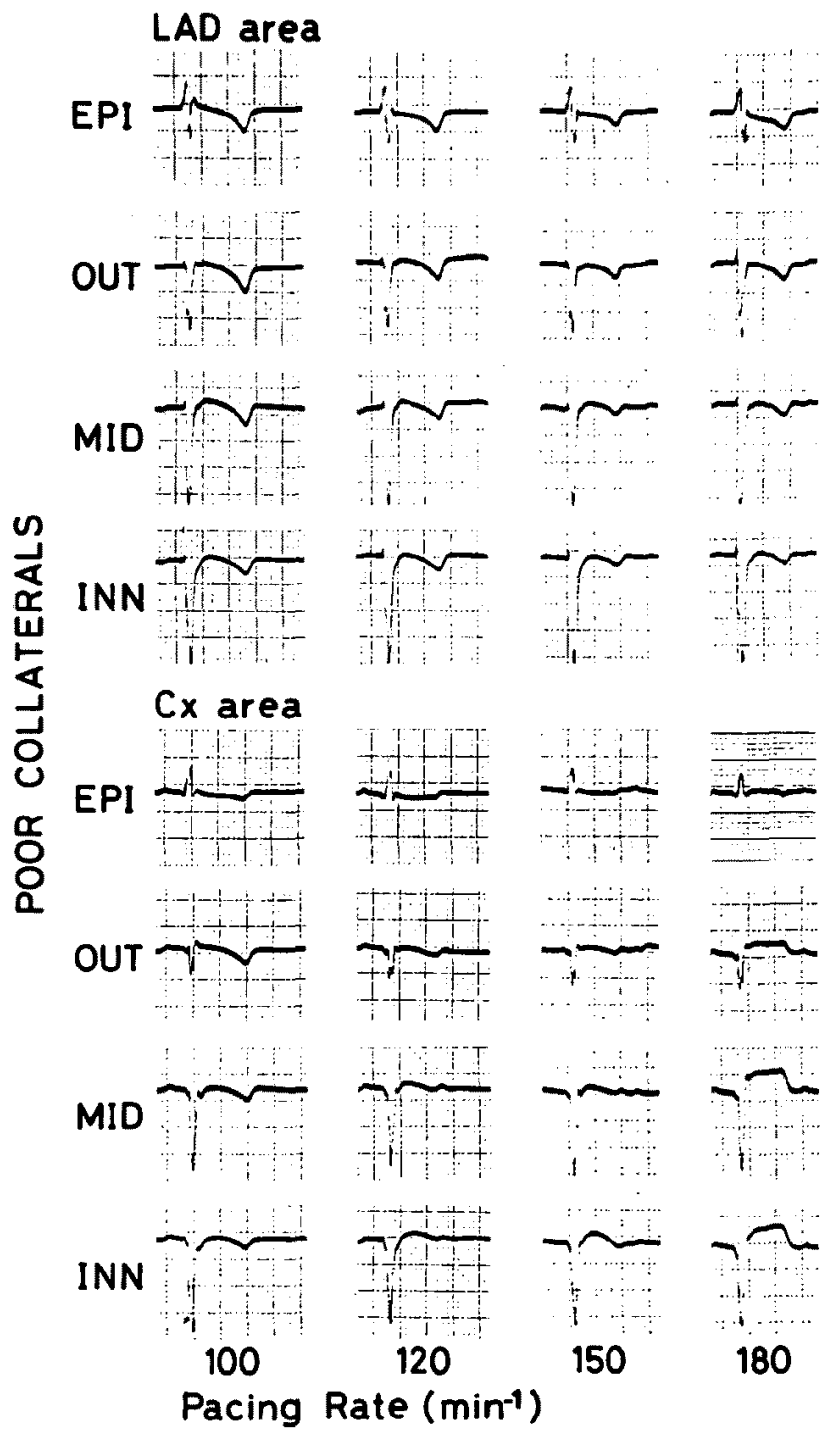

Fig. 5. Representative electrographic changes produced by pacing-induced tachycardia in the presence of coronary constriction in a control dog with poor collaterals. LAD $=$ left anterior descending artery; $\mathrm{Cx}=$ circumflex artery; $\mathrm{EPI}=$ epicardium; $\mathrm{OU} T=$ outer layer; $\mathrm{MID}=$ middle layer $; \mathrm{INN}=$ inner layer.

4. Electrocardiographic ST-segment changes in dogs with developed collaterals

No abnormal $Q$ waves were observed in the epicardial electrograms of any animal with implantation of ameroid constrictor. In dogs with moderate collaterals, there was no significant change in the ST-segment from the $\mathrm{Cx}$ area at pacing rates of up to $150 / \mathrm{min}$. Pacing-induced tachycardia 

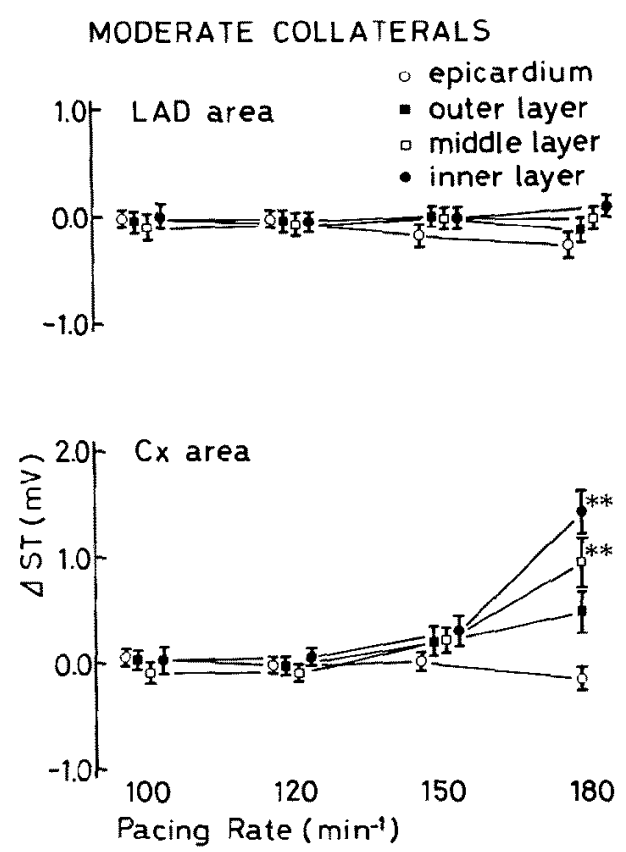

Fig. 6. $2 S T$ changes from LAD and Cx areas produced by pacing-induced tachycardia in the presence of coronary constriction in dogs with moderate collaterals. $\mathrm{LAD}=$ left anterior descending artery; $\mathrm{Cx}=$ circumflex artery. **: significantly different from resting values at $p<0.01$.

at a rate of $180 / \mathrm{min}$, however, produced $\mathrm{ST}$-segment elevation of $1.41 \pm 0.18$ $\mathrm{mV}$ in the inner layer and $0.96 \pm 0.24 \mathrm{mV}$ in the middle layer from the $\mathrm{Cx}$ area. No significant changes were seen in the LAD area at any pacing rate (Figs. 6 and 7A).

In dogs with abundant collaterals, there was no significant ST-segment change in any electrogram from the $\mathrm{Cx}$ or LAD areas during coronary constriction plus pacing-induced tachycardia (Figs. 7B and 8).

\section{Discussion}

Our results show that collateral vessels have preventive effects on the myocardial ischemia produced by graded increases in metabolic requirements under conditions of limited coronary flow reserve in an experimental model simulating angina pectoris. In this study, regional myocardial ischemia was detected by epicardial and intramyocardial electrograms. It has been reported that a close relationship exists between ST-elevation seen on an intramyocardial electrogram and the degree of regional myocardial ischemia determined by means of intramyocardial gas tensions, local tissue flow and re- 

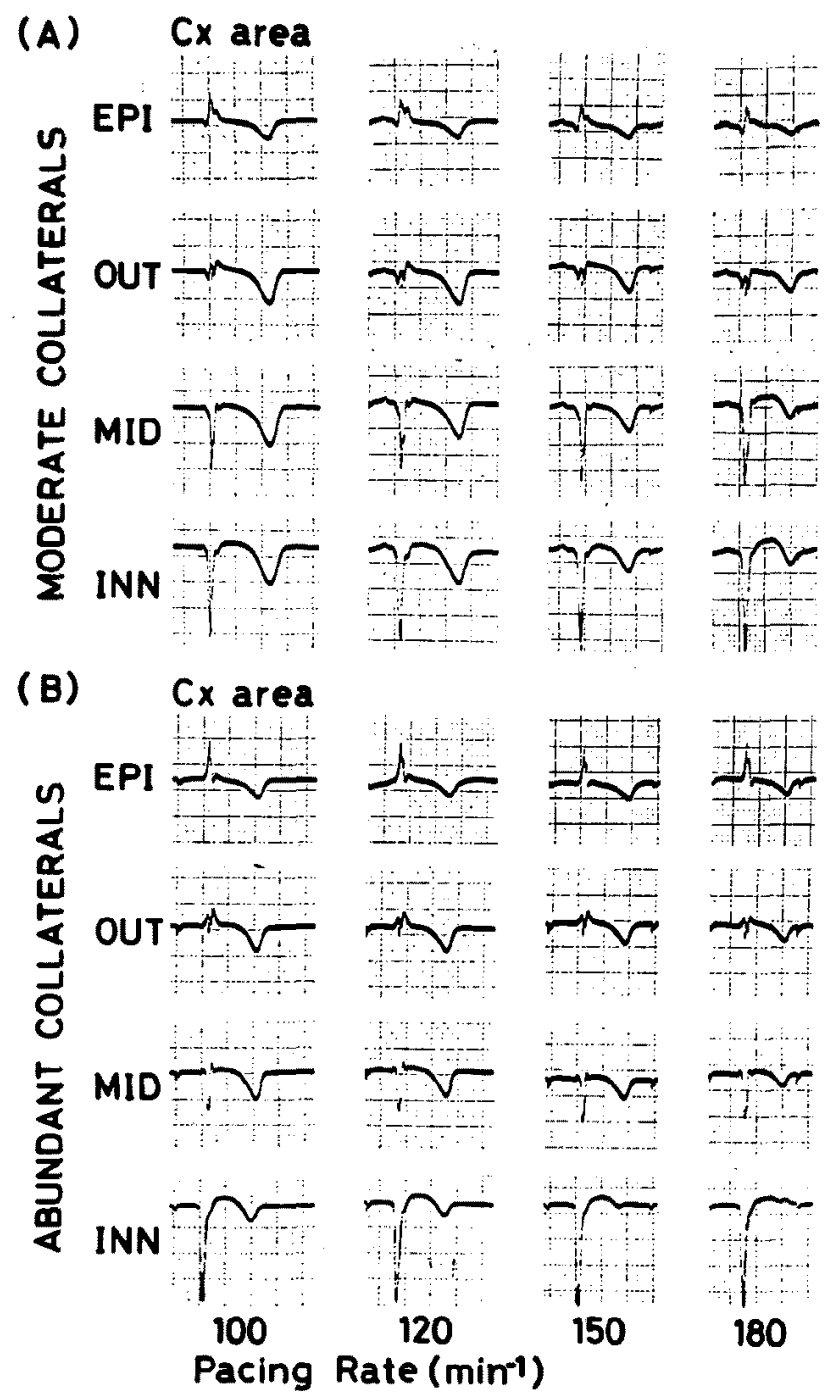

Fig. 7. Representative electrographic changes produced by pacing-induced tachycardia in the presence of coronary constriction in dogs with moderate (A) and abundant collaterals (B). $C x=$ circumflex artery; EPI=epicardium; $\mathrm{OUT}=$ outer layer; $\mathrm{MID}=$ middle layer; $\mathrm{INN}=$ inner layer.

gional myocardial contraction. ${ }^{2)-4)}$ ST-elevation on the intramyocardial electrogram was closely related to an increase in carbon dioxide tension in the corresponding region. Therefore, the regional intramyocardial electrogram more closely reflects local ischemia than does an epicardial electrogram.

Cardiac pacing is one effective technique for increasing myocardial oxygen consumption. ${ }^{7)}$ In this experiment heart rate was regulated by atrial pacing at rates of $100,120,150$, and 180/min without significant changes in 

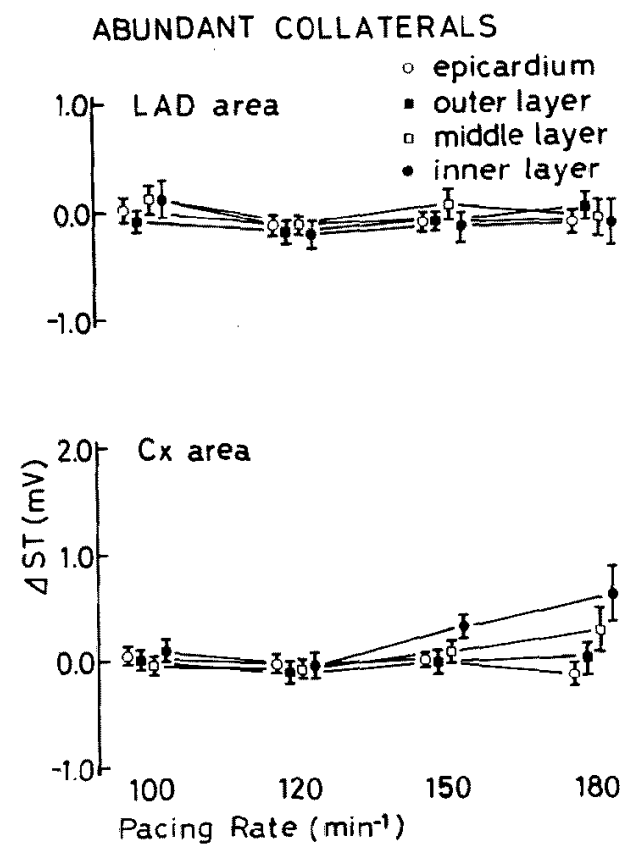

Fig. 8. $4 \mathrm{ST}$ changes from LAD and $\mathrm{Cx}$ areas produced by pacing-induced tachycardia in the presence of coronary constriction in dogs with abundant collaterals. $\mathrm{LAD}=$ left anterior descending artery; $\mathrm{Cx}=$ circumflex artery.

aortic blood pressure and flow in any group. Only LVEDP was elevated slightly at a rate of $180 / \mathrm{min}$. In the absence of coronary stenosis, increases of heart rate resulted in an increase in $\mathrm{Cx}$ coronary blood flow $(\mathrm{r}=0.9)$ while the ST-segment remained at resting levels. These data show that atrial pacing within a range of $100-180 / \mathrm{min}$ is a reliable method for increasing myocardial metabolic requirements without affecting systemic hemodynamics.

When the circumflex coronary artery was stenosed to produce an $80 \%$ reduction of internal diameter in control dogs, coronary blood flow was reduced to $74 \%$ of the pre-constriction value in the resting state and was not increased by pacing-induced tachycardia. The ST-segment in electrograms from the $\mathrm{Cx}$ area was significantly elevated, showing subendocardial ischemia at a rate of $150 / \mathrm{min}$ and transmural ischemia at a rate of $180 / \mathrm{min}$. This is partly due to augmentation of the oxygen demand by tachycardia, and an inability to augment blood supply through the stenotic coronary artery. A decrease in the diastolic period during which the subendocardial layer could be perfused might have been an additional factor. It is clear that under restricted coronary artery inflow in control dogs the blood supply to the affected myocardium via collaterals was insufficient to compensate for the augmented 
metabolic requirements induced by pacing. ST-elevation in the electrogram from the $\mathrm{Cx}$ area first appeared in the inner layer and then proceeded in an outer direction with graded increases in metabolic requirements induced by atrial pacing. These findings are consistent with results previously reported, ${ }^{8}$ and support the concept that the regional electrogram is useful in detecting the degree and extension of myocardial ischemia.

The dogs with developed collaterals produced by applying an ameroid constrictor around the circumflex coronary artery were divided into 2 groups by collateral indices. In dogs with moderate collaterals, pacing-induced tachycardia at a rate of $180 / \mathrm{min}$ under fixed stenosis of the coronary artery produced ST-elevation in electrograms from the inner and middle layers of the $\mathrm{Cx}$ area. In dogs with abundant collaterals, on the other hand, no significant ST-elevation was found in any electrograms recorded under the same conditions. Nor were there any significant changes in circumflex coronary inflow in dogs with moderate or abundant collaterals. These findings suggest that the blood supply through the developed collateral channels protects the myocardium from ischemic injury, which is in contrast to the results seen in the control dogs. In addition, the functional capacity of collateral vessels seems to be related to the extent of collateral vessel development. Therefore, blood flow available through developed coronary collaterals is capable of adequately perfusing the affected myocardium to meet the increased metabolic requirement caused by pacing-induced tachycardia under condition of limited coronary flow reserve.

Previous experimental studies demonstrated the beneficial effects of the coronary collaterals on regional blood flow, ${ }^{9)}$ electrocardiographic ST-segment change, ${ }^{10)}$ ventricular fibrillation threshold, ${ }^{11)}$ regional myocardial contraction, ${ }^{12), 13}$ ) and survival rate after coronary ligation. ${ }^{14}$ Howcver, most chronic experiments concerned with an ameroid constrictor were performed under conditions where the primary channel was completely closed by the constrictor as a model of myocardial infarction. ${ }^{9-14)}$ When stenosis is applied to a primary artery, streams of blood through collaterals and primary channels conflict and influence each other. Whether obstruction of the primary channel is total or partial should affect the function of the collateral blood supply to the ischemic myocardium. This study was thus designed to define the preventive effects of collaterals on ischemic injury in an animal model with those physiologic features thought to be associated with angina pectoris. The results confirm the beneficial effects of collaterals in this condition. However, it might be difficult to apply these results to humans, since the collateral indices in man show poor development of collaterals in comparison with those in the dog. 


\section{REFERENCES}

1. Griggs DM, Nakamura Y: Effect of coronary constriction on myocardial distribution of iodo-antipyrine $\mathrm{I}^{131}$. Am J Physiol 215: 1082, 1968

2. Mizutani T, Yokoyama M, Fujiwara K, Mackawa K, Azumi T, Katada Y, Fukuzaki H: Relationship between epicardial and intramyocardial ST-segment voltage and myocardial blood fow during graded coronary constriction in the dog. Basic Res Cardiol 74: 518, 1979

3. Maekawa K, Katada Y, Azumi T, Ishikawa Y, Fujiwara K, Yokoyama M, Mizutani T, Okamoto R, Fukuzaki $\mathrm{H}$, Tomomatsu $\mathrm{T}$ : An experimental study on coronary insufficiency. Effect of graded coronary constriction on epicardial and intramyocardial electrograms and gas tensions. Jpn Circulat J 41: 739, 1977

4. Mizutani T, Yokoyama M: Electrocardiographic ST-elevation. Its sensitivity and limitation as an index of myocardial ischemia. Jpn Circulat $\mathrm{J}$ 44: 188, 1980

5. Schaper W, Wüsten B, Flameng W, Schlotholt J, Winkler B, Pasky S: Local dilatory reserve in chronic experimental coronary occlusion without infarction. Basic Res Cardiol 70: 159, 1975

6. Katada Y, Mizutani T, Maekawa K, Azumi T, Fujiwara K, Yokoyama M, Fukuzaki H: An electrographic study on the functional capacity of the coronary collateral circulation in dogs with chronic coronary occlusion. Jpn. Circulat J 44: 294, 1980

7. Sonnenblick EH, Ross J Jr, Braunwald E: Oxygen consumption of the heart. Newer concepts of its multifactoral determination. Am J Cardiol 22: 328, 1968

8. Neill WA, Oxendine J, Phelps N, Anderson RP: Subendocardial ischemia provoked by tachycardia in conscious dogs with coronary stenosis. Am J Cardiol 35: 30, 1975

9. Flameng W, Schwarz F, Schaper W: Coronary collaterals in the canine heart: development and functional significance. Am Heart J 97: 70, 1979

10. Mizutani T, Katada Y, Maekawa K, Yokoyama M, Fukuzaki H: Coronary collateral circulation as an important factor to modify the ischemic injury of the myocardium in coronary ligated dogs. Jpn Heart $\int$ 20: 485, 1979

11. Garza DM, White FG, Hall RE, Bloor CM: Effect of coronary collateral development on ventricular fibrillation threshold. Basic Res Cardiol 69: 371, 1974

12. Tomoike H, Franklin D, Kemper WS, McKown D, Ross J: Functional evaluation of coronary collateral development in conscious dogs. Am J Physiol 241 : H519, 1981

13. Yokoyama M, Mizutani T, Fujiwara K, Azumi T, Fukuzaki H, Tomomatsu T: An experimental study on the role of coronary collateral development in preservation and improvement of contractile force in the ischemic myocardium. Jpn Circulat J 42: 1249, 1978

14. Meesmann W, Schulx FW, Schley G, Adolphsen P: Über Lebensquote nach akutem experimentellen Coronarverschluss in Abhängigkeit von Spontankollateralen des Herzens. $Z$ ges exp Med 153: 246, 1970 